\title{
Knowledge and Perceptions of Preconception Care Among Health Workers and Women of Reproductive Age in Mzuzu City, Malawi. A Cross-sectional Study
}

Mtondera Eness Munthali-Nkhoma ( $\nabla$ mtondera441@gmail.com )

College of Medicine https://orcid.org/0000-0002-4942-7908

Isabel Kazanga-Chiumia

College of Medicine

Chrispin Mandiwa

EGPAF

Saul Mwale

Mzuzu University Faculty of Health Sciences

Research

Keywords: preconception, women of reproductive age, health workers, knowledge, perception, maternal health

Posted Date: February 9th, 2021

DOI: https://doi.org/10.21203/rs.3.rs-178037/v1

License: @ (i) This work is licensed under a Creative Commons Attribution 4.0 International License. Read Full License 


\section{Abstract}

Background: Preconception care is one of the preventive strategies in maternal and new-born health as recommended by WHO. However, in sub-Saharan Africa there is poor preconception care practices. This study examined knowledge and perceptions of preconception care among health workers and women of reproductive age group in Mzuzu city, Malawi.

Methods: A descriptive cross-sectional mixed methods approach utilizing quantitative and qualitative methods was employed. Selection of respondents was done through a multistage and purposive sampling techniques. A total of 253 women of reproductive age from 9 townships of Mzuzu City responded to the questionnaire and 20 health workers were interviewed.

Results: Of the 253 women, $57.7 \%(n=146)$ demonstrated a good level of knowledge of preconception care while $42.3 \%(n=107)$ had poor knowledge level. About $72 \%(n=105)$ of those with good level of knowledge lacked awareness on possibilities of talking to a health care provider on intentions of getting pregnant. About $74.7 \%$ ( $n=189)$ of women had a positive perception towards preconception care. Knowledge level of women was a good predictor of positive perception (AOR $=2.5 ; 95 \% \mathrm{Cl}=1.215-5.023)$, however its prediction capacity varied with the academic level attained. Those with secondary $(A O R=10.2 ; 95 \% \mathrm{Cl}=$ 3.285 - 26.276) and tertiary ( $\mathrm{AOR}=2.3 ; 95 \% \mathrm{Cl}=1.146-4.952)$ were more likely to have good knowledge than those with primary school level education. About $95 \%(n=19)$ of health workers lacked details about preconception care but they admitted their role in preconception care.

Conclusion: Preconception care practice among health workers and women of reproductive age in Mzuzu City is low but there is positive perception towards preconception care among both parties. There is an opportunity in existing platforms for implementation of interventions targeting identified predictors for increased knowledge and uptake of preconception care.

\section{Plain English Summary}

World health organization defines preconception care as the provision of biomedical, behavioral and social interventions to women and couples before the occurrence of conception. In sub-Saharan Africa, there is poor preconception care practices which has resulted into high infant and maternal mortalities. This study examined the knowledge and perceptions of preconception care among health workers and women of reproductive age in order to provide evidence based outcomes for tailored interventions and policy direction. A semi-structured questionnaire and structured interviews were used to assess the knowledge level and perceptions of preconception care among women of reproductive age and health workers respectively.

Of the 253 women, more than half $(57.7 \%)$ showed good level of knowledge of preconception care while $42.3 \%$ had poor knowledge level. Most (72\%) women with good knowledge level lacked awareness that they can talk to a health worker before getting pregnant. Most $(74.7 \%)$ women showed a positive perception towards preconception care which was strongly linked to having good knowledge based on the academic level attained. Those with secondary and tertiary backgrounds were more likely to have good knowledge 
than those with primary school level education. The majority (95\%) of health workers were unable to explain well about preconception care but they admitted their role in preconception care.

\section{Background}

Preconception care is one of the preventive strategies in Maternal and Newborn Health (MNH) as recommended by World Health Organization (WHO) and is considered to be feasible to both developed and developing worlds [1]. MNH still remains a global health concern. WHO states that even where strong public health programme are in place across the life-course, they do not guarantee that women enter pregnancy in good health [2]. Therefore, it is necessary that certain steps should be taken before conception or early in pregnancy to maximize positive health outcomes, hence provision of preconception care is highly recommended [1]. The emerging globalization health risk factors like overweight, tobacco use among women is common in many countries from developed to developing countries; hence just focusing on perinatal, intrapartum and postnatal is not enough to reduce the infant and maternal mortality [2]. This is why preconception care should not be limited to developed and emerging economies. It is important to take the opportunity that more women today have access to education and information, are employed, have personal income and decision making power, and delay pregnancy, thereby having many opportunities to inform them about the need for preconception care and a healthy reproductive life [2]. Therefore, making preconception care available can have trans-generational impact on some women; those who are aware of such opportunities and can access such services. Our responsibility as health care providers is to provide that opportunity.

WHO recommended implementation of preconception care 7 years ago, unfortunately there is no global consensus on the place of preconception care as part of an overall strategy to prevent maternal and childhood mortality and morbidity. In 2011 sub-Saharan Africa report on maternal health indicated a poor preconception care practice in a good number of sub-Sahara African countries largely due to low economic status, lack of health care providers, illiteracy and poor awareness about maternal health including preconception care [3]. Likewise, in Malawi there is no policy nor guidelines to direct preconception care services and there are no indicators to capture preconception care health services [4]. Further, literature on women and health worker's knowledge and perceptions of Preconception care as an impetus for their ability to undertake or provide health care activities is limited. Despite Malawi being reported to have very high maternal and neonatal mortality rates of 439 per 100,000 and 27 per 1,000 live births respectively [4]. Consequently, $33 \%$ of the pregnancies result in prematurity while $9.9 \%$ develop congenital abnormalities [5]. Since the content and means of delivery of preconception care are national and local health systems context specific and influenced by the economic realities of different countries [6]. Additionally, the knowledge level and perceptions held by the providers of preconceptions care services in different settings influences the way they engage, discuss and deliver preconception care activities to prospective parents [7]. Understanding the available platforms, knowledge level and perceptions of key actors in preconception care practice is crucial for increased uptake of tailored interventions and proper policy direction. The study therefore examined the knowledge and perceptions of preconception care among health workers and women of reproductive age group in Mzuzu City, Malawi. 


\section{Methodology}

\section{Study setting}

Malawi as a country is divided into three distinct regions namely; northern, central and southern. The northern region is reported to have the highest antenatal care coverage of $46 \%$ and $92 \%$ skilled birth attendance [8]. The study was conducted in Mzuzu City which is located in the northern region of Malawi with a land area coverage of 48 square kilometers and a population of 220,000 people [9]. Atleast $60 \%$ of Mzuzu population resides in informal settlements [9]. Study participants were drawn from the nine townships of Mzuzu City based on their geographical area population [10] namely: Chibanja, Chibavi, Mchengautuba, Katoto, Masasa, Zolozolo, Chiputula, Katawa and Luwinga (Figure 1). The study was conducted from June 2018 to October 2019.

\section{Study design, sample size and sampling techniques}

The study employed a descriptive cross sectional mixed methods design using quantitative and qualitative approaches. Semi-structured questionnaires (See Supplementary File 1) and interview guides (See Supplementary File 2) were used as instruments for collecting quantitative and qualitative data from women of child bearing age and health workers respectively.

The sample size was determined by using a single population proportion formula with the following assumptions; $P=23 \%$ (50,600 women of the reproductive age group against a population of 220,000, [3], $95 \%$ level of significance $(a=0.05), Z a / 2=1.96,5 \%$ margin of error $(d=0.05)$. The total sample size was 272 , however due to non-response through withdrawal from the study 253 was used. A multistage cluster sampling was employed to draw women of child bearing age from nine townships of Mzuzu City while purposive sampling technique was used to select 20 skilled birth attendants. Semi-structured questionnaires were pretested on $10 \%$ of respondents outside the target population, modified and used to collect demographic characteristics, level of knowledge on preconception care. Knowledge of preconception care was assessed using the following questions according to [11, 12]

a. Factors that can help promote good pregnancy such as eating a balanced diet, avoiding smoking and drinking alcohol, visiting a Gynecologist/ Hospital, taking vitamins and exercising.

b. Some of the issues that can affect fetal development such as trauma, use of over the counter drugs, use of natural Herbs/Chemicals, lack of Vitamins/ Folic acid, drinking alcohol and smoking

c. Awareness of a baby being born with problems?

d. Awareness about folic acid tablets and when it is to be taken?

Good knowledge was rated based on the ability of a woman to answer three or more questions correctly. Whilst those that answered less than three questions correctly were rated to have had poor knowledge. Health worker's knowledge of preconception care was assessed using question one to six. Perception was assessed through asking women whether they felt that preconception care is beneficial. Those that said it was beneficial were rated as having positive perception and those that said it was not beneficial were rated as having negative perception. 


\section{Data Collection and Management}

The quantitative study used questionnaires [11, 12], whilst the qualitative study used interview guides for data collection. The questionnaire was developed in excel then uploaded on field task software capturing demographic data, level of knowledge on preconception care and factors that can influence access to preconception care from women of child bearing age. The questions asked were related to knowledge of folic acid, promotion of good pregnancy, factors that can affect fetal development and awareness of fetus developing congenital anomalies.

Semi-structured interviews were used to collect data on knowledge and perceptions of health workers on preconception care. Interviews were recorded using a tape recorder.

\section{Data analysis}

Quantitative data was analyzed using a statistical package for social scientists (SPSS) version 20. Descriptive statistics involved generation of frequency distributions of demographic characteristics. Inferential statistics through a Pearson chi-square test was used to measure the association of age, marital status, education level, number of children family planning history with perception and knowledge level. A multivariate logistic regression was performed on factors that were significantly associated with perception and knowledge level at bivariate level of analysis $(p<0.05)$ to determine adjusted odds ratios $(A O R)$. The Odds Ratios (OR) associated with these factors were reported as a measure of strength, together with the respective 95\% Confidence Intervals. Qualitative data from key informant interviews transcriptions were analyzed thematically and were presented as textual expressions and direct quotations.

\section{Results}

\section{Socio-demographic characteristics of respondents}

Among the 253 women who participated in this study, $45.8 \%$ of the women were young women aged between 15 to 24 years. At least $38.3 \%$ of women had gone up to secondary school. About $63.3 \%$ of women had children with $34 \%$ of them having 5 or more children. Nearly one third of the women $(31.6 \%)$ were still in School. Over half $(54.2 \%)$ of the women had ever used family planning. $48.2 \%$ of the women were married while $36 \%$ were single and $11.9 \%$ were divorced (Table 1 ). 
Table 1

Socio-demographic characteristics of women of reproductive age

\begin{tabular}{|c|c|c|}
\hline Characteristics & Frequency & $\%$ \\
\hline \multicolumn{3}{|l|}{ Age } \\
\hline $15-24$ & 116 & $45.8 \%$ \\
\hline $25-34$ & 82 & $32.40 \%$ \\
\hline $35-49$ & 55 & $21.70 \%$ \\
\hline \multicolumn{3}{|l|}{ Education level } \\
\hline None & 5 & $2.0 \%$ \\
\hline primary & 76 & $30.0 \%$ \\
\hline secondary & 97 & $38.3 \%$ \\
\hline Tertiary & 75 & $29.6 \%$ \\
\hline \multicolumn{3}{|l|}{ Occupation } \\
\hline Student & 80 & $31.6 \%$ \\
\hline house wife & 67 & $26.5 \%$ \\
\hline Business & 64 & $25.3 \%$ \\
\hline Working class & 41 & $16.2 \%$ \\
\hline \multicolumn{3}{|l|}{ Marital Status } \\
\hline Single & 91 & $36.0 \%$ \\
\hline Married & 122 & $48.2 \%$ \\
\hline Divorced & 30 & $11.9 \%$ \\
\hline Widowed & 10 & $4.0 \%$ \\
\hline \multicolumn{3}{|c|}{ Number of children } \\
\hline None & 93 & $36.8 \%$ \\
\hline 1 to 2 & 51 & $20.2 \%$ \\
\hline 3 to 4 & 23 & $9.1 \%$ \\
\hline 5 or more & 86 & $34.0 \%$ \\
\hline \multicolumn{3}{|c|}{ Family Planning history } \\
\hline Yes & 116 & $45.8 \%$ \\
\hline No & 137 & $54.2 \%$ \\
\hline
\end{tabular}


Out of the 20 health workers, 11 were between the ages of $20-34$ representing $55 \%$. Most health workers (11) were Nurse-Midwife Technicians (Table 2).

Table 2

Socio demographic data of health workers for the qualitative study

\begin{tabular}{|lll|}
\hline Characteristics & Frequency & $\%$ \\
\hline Age & & \\
$30-34$ & 11 & $55 \%$ \\
$45+$ & 3 & $15 \%$ \\
Gender & 6 & $30 \%$ \\
Male & & \\
Female & 6 & $30 \%$ \\
Specialization & 14 & $70 \%$ \\
Gynaecologist & & \\
Medical Doctor & 1 & $5 \%$ \\
Clinical Officer & 1 & $5 \%$ \\
Nurse-Midwife Officer & 6 & $5 \% \%$ \\
Nurse-Midwife Technician & 11 & $55 \%$ \\
\hline
\end{tabular}

Table 3

Health workers summarized correct responses in some key variables of preconception care

\begin{tabular}{|lll|}
\hline Variables & Frequency $(\mathrm{n}=20)$ & $\%$ \\
\hline Information to women intending to get pregnant & 1 & 5 \\
\hline Management of women with chronic conditions & 3 & 15 \\
\hline Management of women who delivered babies with congenital anomalies & 6 & 30 \\
\hline Management of women with obstetric complications & 3 & 15 \\
\hline Knowledge about preconception care & 2 & 10 \\
\hline Role in preconception care & 20 & 100 \\
\hline
\end{tabular}




\section{Predictors of PCC from Bivariate and multivariate logistic regression analysis}

\section{Perception}

The association of categorical variables based on Pearson chi-square showed that marital status (Chi-stat = 27.83, $p<0.001)$, occupation (Chi-stat $=9.78, P<0.05)$, education level $($ Chi-stat $=9.62, P<0.05)$ significantly associated with perception on PCC, Table 4. 
Table 4

Predictors of PCC from Bivariate and multivariate logistic regression analysis $(* p<0.05, * \star p<0.01, * \star \star p<$ 0.001 )

\begin{tabular}{|c|c|c|c|c|c|c|c|c|}
\hline & \multicolumn{4}{|c|}{ Perception } & \multicolumn{4}{|c|}{ Knowledge } \\
\hline & positive & negative & Chi-stat & AOR & Good & Poor & Chi-stat & AOR \\
\hline \multicolumn{9}{|l|}{ AGE } \\
\hline $15-24$ & 88 & 28 & & & 74 & 42 & & \\
\hline $25-34$ & 58 & 24 & 0.88 & & 47 & 35 & 5.67 & \\
\hline $35-49$ & 43 & 13 & & & 25 & 30 & & \\
\hline $\begin{array}{l}\text { MARITAL } \\
\text { STATUS }\end{array}$ & & & & $\star * \star$ & & & & \\
\hline Single & 59 & 34 & $27.83^{\star \star \star}$ & & 51 & 40 & 1.63 & \\
\hline Married & 145 & 15 & & $\begin{array}{l}4.29 \\
(\mathrm{Cl}, 1.97- \\
9.37)\end{array}$ & 104 & 58 & & \\
\hline \multicolumn{5}{|c|}{ NUMBER OF CHILDREN } & & & \multicolumn{2}{|l|}{$27.43^{\star \star \star}$} \\
\hline NONE & 73 & 20 & & & 47 & 46 & & \\
\hline 1 to 2 & 39 & 13 & & & 25 & 27 & & \\
\hline 3 to 4 & 18 & 6 & 1.94 & & 7 & 17 & & \\
\hline 5 plus & 59 & 26 & & & 66 & 18 & & \\
\hline OCCUPATION & & & & * & & & & \\
\hline NONE & 56 & 11 & & 0 & 25 & 42 & & \\
\hline STUDENT & 50 & 30 & $9.78 *$ & $\begin{array}{l}3.27(\mathrm{Cl} \\
1.06-10.12)\end{array}$ & 67 & 13 & 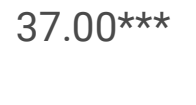 & \\
\hline BUSINESS & 50 & 14 & & $\begin{array}{l}0.69(\mathrm{Cl}, 0.25- \\
1.89)\end{array}$ & 32 & 32 & & \\
\hline EMPLOYED & 32 & 10 & & $\begin{array}{l}0.99(\mathrm{Cl}, \\
0.38-2.54)\end{array}$ & 21 & 20 & & \\
\hline \multicolumn{9}{|l|}{ FP HISTORY } \\
\hline YES & 83 & 34 & 1.37 & & 79 & 38 & $8.95^{\star \star}$ & \\
\hline NO & 106 & 30 & & & 66 & 70 & & \\
\hline $\begin{array}{l}\text { EDUCATION } \\
\text { LEVEL }\end{array}$ & & & & & & & & $\star \star$ \\
\hline NONE & 4 & 1 & & & 2 & 2 & & \\
\hline PRIMARY & 60 & 16 & $9.62^{*}$ & & 25 & 51 & $45.79 * \star$ & 0.67 \\
\hline
\end{tabular}




\begin{tabular}{|c|c|c|c|c|c|c|}
\hline & & & & & & $\begin{array}{l}(\mathrm{Cl}, \\
0.09- \\
4.58)\end{array}$ \\
\hline SECONDARY & 79 & 19 & 54 & 44 & & $\begin{array}{l}1.54 \\
(\mathrm{Cl}, \\
0.23- \\
10.53)\end{array}$ \\
\hline TERTIARY & 46 & 29 & 65 & 10 & & $\begin{array}{l}4.72 \\
(\mathrm{Cl}, \\
0.58- \\
38.09)\end{array}$ \\
\hline Perception & & & & & & * \\
\hline Positive & & & 96 & 92 & $11.68^{* *}$ & $\begin{array}{l}0.42(\mathrm{Cl}, \\
0.21- \\
0.85)\end{array}$ \\
\hline Negative & & & 49 & 16 & & \\
\hline
\end{tabular}

After multivariate analysis was performed, marital status and occupation were found to be predictors of perception of PCC. Those that were married were more likely to have good perception towards PCC (AOR $4.29 ; \mathrm{Cl}=1.97-9.37)$ than those who were single. Those who were married and going to school were more likely to have positive perception than those who were housewives (AOR 3.27; $\mathrm{Cl}=1.06-10.12$ ).

\section{Knowledge}

There was no association between age and level of knowledge on PCC (Table 4). There was also no association between marital status and level of knowledge on PCC. Number of children is highly associated with level of knowledge on PCC (Chistat=27.43, P<0.001). Occupation was also highly associated with level of knowledge on PCC (Chistat $=37.00, P<0.001)$. History of family planning use is associated with level of knowledge on PCC (Chistat $=8.95, P<0.01)$. Education level was associated with level knowledge on PCC (Chistat $=45.79, \mathrm{P}<0.01$ ). Perception was associated with level of knowledge on PCC (Chistat=11.68, $\mathrm{P}<0.01)$.

After multivariate analysis was performed perception and level of education were found to be predictors of level of knowledge of preconception care. Those that had good knowledge were more likely to have a positive perception towards PCC (AOR 0.42; $\mathrm{Cl}=0.21-0.85$ ). The higher the level of education the greater the level of knowledge. Those with tertiary education were more likely to have good knowledge than those that had none (AOR 4.72; $\mathrm{Cl}=0.58-38.09$ ).

Most women were able to outline eating a balanced diet as one of the things needed to promote a healthy pregnancy $(77.04 \%)$. A few outlined engaging the hospital (29.57\%), conducting exercises $(27.63 \%)$, avoiding smoking and alcohol (16.34\%) and taking vitamins $(15.95 \%)$ as a way of promoting a healthy pregnancy. Furthermore, women outlined drinking and smoking (37.35\%), over the counter drugs (22.57\%), 
use of herbs and chemicals (20.62\%), trauma (20.62\%) and lack of vitamins (19.07\%) as some of the issues that can affect fetal development. $97.28 \%$ of the women did not know anything about folic acid and only $1.95 \%$ were able to say when it is to be taken.

Results from the qualitative interviews showed that most of the health workers knew the definition of preconception care "as the care which a woman receives before conceiving" but lacked details about the process and what services to offer to clients during preconception care (Table 3). The textual expressions of some of the health workers are reported below.

"Well I know that preconception care is care offered to a woman before she becomes pregnant in order to correct risks that were there but as a nurse I just refer to clinicians so I do not do much (laughs).

(Respondent 3, Mzuzu Central Hospital).

"Mmmm, preconception care is the care that is offered to women before they conceive but due to capacity it is offered to high risk women. It prepares the woman before pregnancy, prepares psychologically, prepares complications and also helps to stabilize those that have condition like hypertension before they conceive." (Respondent 4, Mzuzu central hospital).

\section{ROLES AND RESPONSIBILITY OF HEALTH WORKERS ON PRECONCEPTION CARE}

Qualitative results showed that the majority $(100 \%)$ of health workers recognized that they have a role to play in preconception care services (Table 3). The respondents cited counselling, guidance and provision of the actual services, advocating with the government and other stakeholders, community sensitization and formulation of the preconception care package as some of the roles which they are supposed to do. They had a positive perception towards preconception care. Health workers felt that women also have a role to demand preconception care services and to seek the services. Some of the respondents were quoted as follows:

"As a health worker, it's my duty to advocate for preconception care with the government, do sensitizations of health workers, and help formulate the preconception care package." (Respondent 4, Mzuzu Central Hospital).

"I, am responsible to give health education to women on preconception care." Respondent 13, Mzuzu Health centre".

\section{Discussion}

Implementation of preconception care depends on health care worker's knowledge [13]. The study has demonstrated that the majority of health workers did not have sufficient knowledge to provide preconception care or offer care to women with complications (Table 3). This is similar to a study that was done in Ethiopia in 2018, which also reported poor knowledge level among health workers [14]. Further, the study has shown that the level of knowledge of preconception care was dependent on area of specialization with clinicians being knowledgeable than nurses. Similar findings on variation in knowledge and practice for preconception care among health workers were reported in Iran, Khoy city [15]. The difference in knowledge 
level of health workers could possibly be due to lack of standardized preconception care content incorporated in nurses and clinician training curricula. Additionally, lack of standardized guidelines on preconception care could also have contributed to this disparity in knowledge level. Since, the capacity to offer preconception care service to clients depends on health worker's attitude and perceptions. This study has demonstrated that health workers had a positive perception towards preconception care as they recognized it as an essential service. This aligns well with the findings of the study that was conducted in Malawi that assessed health worker attitudes about childbearing and safer conception at two HIV clinics [16]. The study looked at health worker's ability and willingness to counsel HIV clients on family planning methods and child spacing issues. The study revealed the willingness of health workers to discuss preconception counselling with HIV clients [16]. This is an opportunity to build on, according to the health belief model (HBM) perceived benefits can influence someone to seek or provide preconception care services.

The HBM suggests that the more knowledgeable someone is about a risk the more they are likely to engage in health promoting behavior. Results from this study showed fair knowledge though with poor practice of seeking preconception care. Contrary to a poor knowledge level as well as poor practice of seeking preconception care reported in a study conducted in Zambia [17]. Another study in Ethiopia also found that level of women's knowledge of preconception care is relatively low [14]. Therefore, it is important to deliver health education about preconception care to women in order to increase their knowledge as well improve their health seeking behavior as many did not know it was possible to contact a health care provider before conceiving. Furthermore, studies conducted in Sri Lanka, Nigeria and Sudan showed that the women's level of knowledge regarding preconception care is very low. The studies recommended that in settings where there is low awareness of preconception care, promotion of preconception care among reproductive age group women is important to boost maternal health care services and to reduce complications during antenatal care, institutional delivery and postnatal care [18-22]. Further, the study has established that knowledge level of preconception care among women of reproductive age group was determined by the level of education attained. The likelihood of having good knowledge level of preconception care was higher among those who attained tertiary education than those with primary education. The results are consistent with previous studies that indicated that most women with higher level of education tend to use preconception care services [11, 13, 18-22]. Having knowledge on susceptibility of women to maternal and newborn complications can influence them to seek and demand preconception care services. Therefore, more efforts need to be taken to strengthen awareness of preconception especially to women who have primary education background as they were the ones with the least knowledge level.

\section{Limitations of the study}

The results of this study should be interpreted in the context of the following limitations. Due to the nature of the study, some women were not comfortable to discuss issues concerning PCC despite all measures being taken to protect study participant's privacy. Recall biasness on how to maintain a good pregnancy and issues that affect foetal development. The study utilized rural and urban populations as respondents making the results generalizable to the current city but not to the whole country. 


\section{Conclusion}

Women of child bearing age in Mzuzu had fair preconception care knowledge though with poor or no health care seeking behavior. The level of education attained influenced their knowledge level and uptake of preconception care. Health worker's knowledge level of preconception care was poor which affected their service provision to women needing preconception care services. Both women of reproductive age group and health workers demonstrated a positive perception towards preconception care which is an entry point to introduce such services. Therefore, there is need to provide guidelines to aid provision of preconception care services.

\section{Abbreviation}

COMREC: College of Medicine Research Ethics Committee, FASD: Fetal Alcohol Spectrum Disorders, GDP: Gross Domestic Product, HBM: Health Belief Model, LMIC: Low-Middle Income Countries, MNH: Maternal and Newborn Health, MMR: Maternal Mortality Rate, NMR: Neonatal Mortality ratio, RHD: Reproductive Health Directorate, SDG: Sustainable Development Goals, URPC: The University Research and Publication Committee, WHO: World Health Organization

\section{Declarations}

\section{Ethics approval and consent to participate}

The research protocol was approved by the College of Medicine Ethics Review Committee (COMREC), approval number P.10/18/2515. Permission to conduct the study was obtained from the Ministry of Health, Malawi. Informed consent was obtained from the District Health Officer and from each respondent. The participants were informed of their right to withdrawal from the study anytime they felt like with no consequences attached. The questionnaire was coded in numbers in order to maintain the confidentiality of the respondents.

\section{Consent for publication}

Not applicable

\section{Availability of data and material}

The datasets used are available from the corresponding author upon reasonable request.

\section{Competing interests}

The authors declare that there are no competing interests

\section{Funding}

This study was partially supported by Sweden Edu Fund 


\section{Authors' contributions}

MM conceived the idea and designed the study, performed the literature search, data collection, performed statistical analysis, interpretation of data and wrote all drafts of the manuscript. IS, SM and CM provided substantial feedback on the drafts of the manuscript. All authors read and approved the final manuscript.

\section{Acknowledgements}

We would like to acknowledge the women and health workers who participated in the study and the Mzimba North and Mzuzu central health institutions for giving us a platform and facility to conduct the study.

\section{Reference}

1. World Health Organization. Preconception care to reduce maternal and childhood mortality. Policy brief, Geneva; 2013. PDF.

2. World Health Organization. Preconception care: maximizing the gains for maternal and child health facts; Policy brief, Geneva 2013. PDF.

3. Dean S, Rudan I, Althabe F, Webb Girard A, Howson C, Langer A, et al. Setting Research Priorities for Preconception Care in Low- and Middle-Income Countries: Aiming to Reduce Maternal and Child Mortality and Morbidity. PLos Med 2013; 10(9).

4. National Statistics Office. Malawi Demographic Health Survey. Malawi Demographic Health Survey. 2016; 2: 3-5.

5. United Nations Children Fund (UNICEF) US. Maternal and Newborn health Disparities, Malawi. 2015 [Accessed on 12:05:20]. Available from: https://data.unicef.org/wpcontent/uploads/country_profiles/Malawi/country\%20profile_M WI.pdf.

6. Poels M, Koster MPH, Franx A, van Stel HF. Parental perspectives on the awareness and delivery of preconception care. BMC Pregnancy and Childbirth. 2017 Sep;17(1):324. DOI: 10.1186/s12884-0171531-1

7. M'Hamdi HI, van Voorst SF, Pinxten W, Hilhorst MT, Steegers EA. Barriers in the uptake and delivery of preconception care: exploring the views of care providers. Matern Child Health J. 2017;21(1):21-28. doi: 10.1007/s10995-016-2089-7

8. UNICEF. Maternal and Newborn Health Disparities. Malawi. Country profile. 2018.pdf

9. Holn R, Kamangira A, Tembo M, Kasulo V, Kandaya H, Gijs-Van-Enk P, et al. Sanitation service delivery in smaller urban areas (Mzuzu and Karonga, Malawi). $2018 \mathrm{Vol}$

10. UN habitat: Regional and technical cooperation Division. Malawi: Mzuzu Urban profile. 2011, HS/086/11E, 978-92-1-13036-7.

11. Coenrod DV, Bruce NC. Knowledge and attitudes regarding preconception care in predominantly lowincome Mexican American People. American Journal of Obstetric Gynecology, 2009;200(6):676: 7.

12. Temel S, Erdem O, Voorham TA, Bonsel GJ, Steegers EA, Denktas S. Knowledge on Preconceptional Folic Acid and Intention to Seek for Preconception Care among men and women in an urban city: A 
population based cross sectional study BMC Pregnancy Childbirth. 2015; 15(1): 1.

13. Mazza D, Chapman A. Improving the uptake of preconception care and periconceptional folate supplementation: what do women think? BMC, 2010; 10: 786.

14. Ayalew Y, Mulat A, Dile M, Simeon A. Women's knowledge and associated factors in preconception care in adet, west gojjam, northwest Ethiopia: a community based cross sectional study. Reproductive Health $2017 ; 15$.

15. Bayrami R, Latifnejad R, Esmaily H. Experiences of women regarding gaps in preconception care services in the Iranian Reproductive Health care system. [Accessed on 13:05:18]. Available from ncbi.nlm.nih.gov.

16. Kawale P, Mindry D, Phoya A, Jansen P, Hoffman RM. Provider attitudes about childbearing and knowledge of safer conception at two HIV clinics in Malawi. 2015;1-7.

17. Mutale $P$, Kwangu M. Knowledge and Preconception care, seeking practices among reproductive-age Diabetic Women in Zambia. International Journal of Translational Medical Research and Public Health. 2017; 1(2):36-43.

18. Ezegwui HU, Dim C, Dim N, Ikeme AC. Preconception Care in South Eastern Nigeria. Obstet. Synae cosl. 2008; 28(8):4 Pub Med.

19. Masoumeh P, Vahid K, Hamid AM, Khosheh K, Samira K. Knowledge of Pregnant Women about congenital Anomalies: A Cross Sectional Study in North of Iran. Indian Journal of Health Science. 2015; $8(1): 41$.

20. Lawal TA, Yusuf OB, Fatiregun AA. Knowledge of Birth Defects among nursing mothers in a developing country. African Health Science. Pud med. 2015; 15 (1)180-7.

21. AL-Kour NA, Sou'Ub R, Mohammad K, Zayed F. Awareness of Preconception Care Among Women and Men a Study from Jordan Journal of Obstetrics and Gynecology, 2015, 35:3, 246-208.

22. Tokunbo OA, Abimbola OK. Awareness and Perception of Preconception Care among Health Workers in Ahmadu. Bello University. Teaching University Zana. Trop Journal of Obstetrics and Gynecology 2016; 33: 149-152.

\section{Figures}




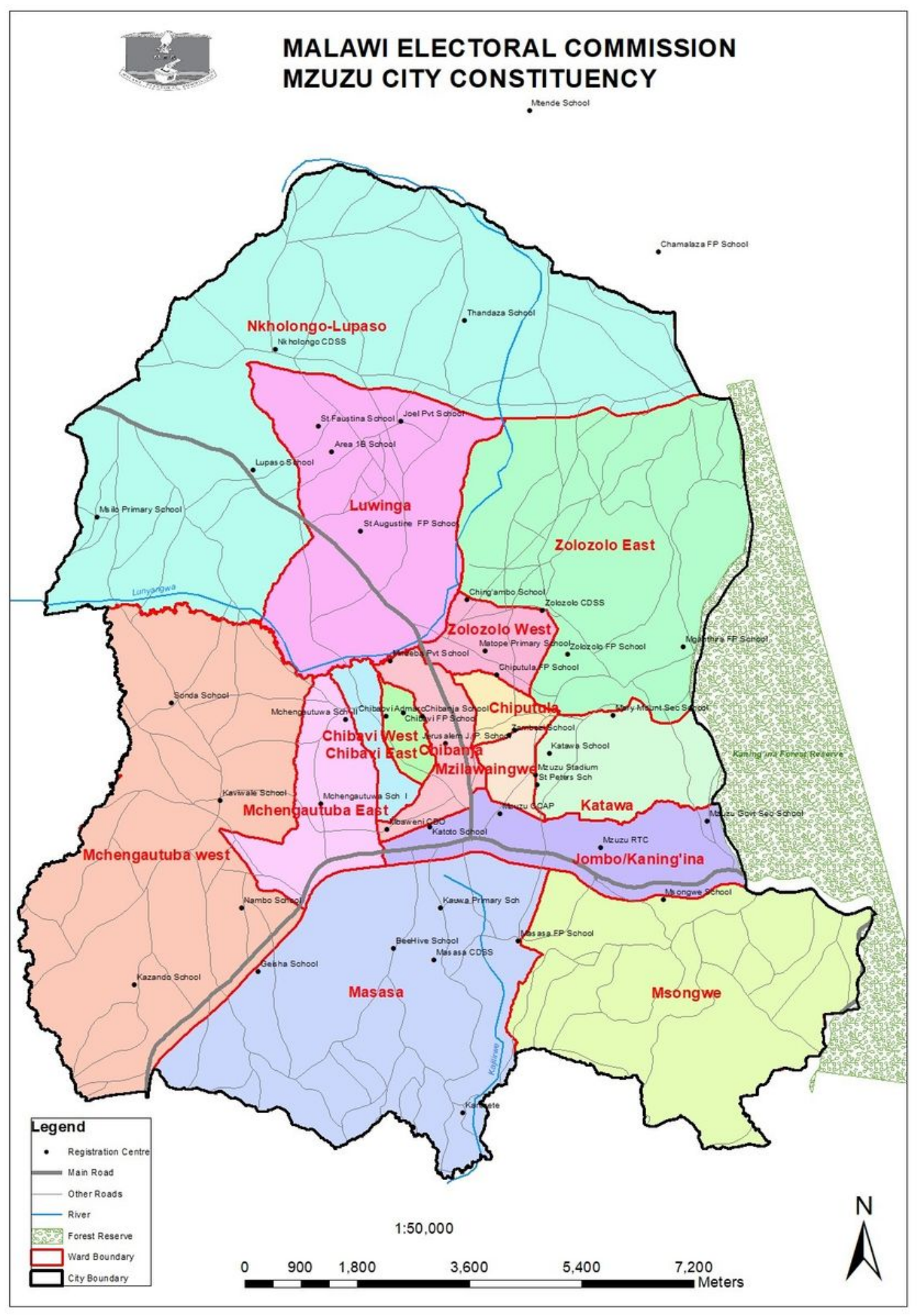

Figure 1

Selected study sites within Mzuzu City where respondents for the study were drawn. Note: The designations employed and the presentation of the material on this map do not imply the expression of any opinion whatsoever on the part of Research Square concerning the legal status of any country, territory, city or area or of its authorities, or concerning the delimitation of its frontiers or boundaries. This map has been provided by the authors. 


\section{Supplementary Files}

This is a list of supplementary files associated with this preprint. Click to download.

- questionnaireBMCpreconceptioncare.docx

- InterviewGuideforHealthWorkersBMC.docx 